\title{
Condições Precárias de Saúde na Ala Feminina do Presídio Nilton Gonçalves: Uma História de Abandono e Sofrimento
}

\section{Luciano de Oliveira Souza Tourinho}

Doutor e mestre em Direito Público - Direito Penal pela Universidade Federal da Bahia. Especialista em Direito Público e em Ciências Criminais pela Faculdade Independente do Nordeste. Graduado em Direito pela Universidade Estadual do Sudoeste da Bahia e pela Faculdade Independente do Nordeste. Professor de Direito Penal e Direito Processual Penal na Universidade Estadual do Sudoeste da Bahia. Professor de Direito Penal, Legislação Penal Extravagante e Direito Processual Penal na Faculdade Independente do Nordeste. Professor de Direito Penal e Processo Penal na Faculdades Santo Agostinho - Vitória da Conquista. Coordenador do curso de Direito da Universidade Estadual do Sudoeste da Bahia, do curso de Direito da Faculdades Santo Agostinho e do Núcleo de Estudos de Direito Contemporâneo - Universidade Estadual do Sudoeste da Bahia. Iuciano.oliveirajus@hotmail.com

\section{Ana Paula da Silva Sotero}

Membro do Núcleo de Direito Contemporâneo - Universidade Estadual do Sudoeste da Bahia. Membro do grupo de pesquisa Culpabilidade, Vulnerabilidade e Seletividade Penal (CNPq). anapaula_sotero@hotmail.com

\section{Nadine Araújo Amorim}

Membro do Núcleo de Direito Contemporâneo - Universidade Estadual do Sudoeste da Bahia. nadineamorim@ hotmail.com

\section{Resumo}

0 presente estudo tem por objetivo analisar e discutir a responsabilidade extracontratual do Estado por via omissiva devido às condições de insalubridade e falta de higiene dos presídios, em especial na ala feminina, a partir do presídio Advogado Nilton Gonçalves, sediado em Vitória da Conquista/BA. 
Assim, nesse aspecto a pesquisa abordará os direitos dos presos previstos pelo ordenamento jurídico brasileiro, buscando verificar a efetividade de tais direitos. Ademais, serão abordadas as funções da pena e sua viabilidade na concretude do sistema carcerário a fim de verificar as condições de saúde da ala feminina da unidade, por meio de entrevistas realizadas com o diretor geral do presídio e com as presas daquele estabelecimento penal. Dentro dessa linha de intelecção, também foi feito estudo de caso da morte da detenta Dalva Santos da Silva, no ano de 2013, dentro do referido presídio. Com base nisso, será analisado a necessidade de responsabilização do Estado diante da omissão do direito à saúde da presa que veio a óbito e das demais presas que ainda se encontram em condições de insalubridade.

Palavras-chave: Condições de insalubridade. Falta de assistência médica. Morte da presa. Omissão do Estado. Responsabilidade do Estado.

\title{
Precarious Health Conditions on the Female Prison Ward Nilton Gonçalves: a History of Abandonment and Suffering
}

\begin{abstract}
This study aims to analyze and discuss the contractual liability of the State through omission due to unsanitary conditions and lack of hygiene in prisons in Brazil, especially in the women's ward. In this respect, the research will address the rights of prisoners provided by Brazilian law, in order to verify the effectiveness of such rights. Moreover, the functions of the pen and its viability in the concreteness of the Brazilian prison system will be addressed. To achieve these goals, it will use the qualitative method, which helps the perception of subjectivities of the studied phenomenon. It will also be used historical and dialectical method, in order to observe and understand the historical and social conditions of the Brazilian prison system. From a qualitative approach, we analyze the reality of prison Nilton Gonçalves, based in Vitoria da Conquista to check the health conditions of the unit's women's wing, through interviews with the director general of the prison and the prey site. Within this intellection line will also be reviewed the death of inmate, Dalva Santos da Silva, in 2013, within the prison without medical care. Based on this, the need for state accountability on the omission of the right to health of the prey that came to death and the other prisoners who are still in unsanitary conditions will be studied.
\end{abstract}

Keywords: Unsanitary conditions. Lack of medical care. Death of prey. Omission of the State. State responsibility.

Recebido em: 22/3/2017

Aceito em: 5/7/2017

\section{Sumário}

1 Introdução. 2 As condições do sistema carcerário brasileiro e a (des)construção do Direito Penal. 3 A inaplicabilidade do princípio da eficiência da administração pública. 4 Responsabilidade extracontratual por omissão do Estado. 5 Presídio regional Advogado Nilton Gonçalves, Vitória da Conquista - BA. 6 Considerações Finais. 7 Referências. 


\section{INTRODUÇÃO}

As condições das prisões do Brasil representam o caos do sistema carcerário brasileiro, marcado, principalmente, pela superlotação das celas e pelas condições precárias de higiene e saúde, que acabam evidenciando o descaso do Estado com o respeito à vida digna dos presos.

A realidade do Direito Penal tem se mostrado ilegítima na medida em que não cumpre o respeito ao princípio constitucional da dignidade da pessoa humana dos condenados e as funções da pena de ressocialização e prevenção do crime, diante de um sistema carcerário superlotado, sem condições físicas de comportar o número elevado de presos.

É notório que as condições precárias de saúde são fundamentais para o grave índice de disseminação de doenças dentro das cadeias, conforme relatório exposto pelas Organização Mundial de Saúde. Segundo Nogueira e Abrahão (2009), o índice de proliferação de doenças na ala feminina tem se tornado cada vez maior devido às condições especiais das mulheres por causa do ciclo menstrual e a sua maior vulnerabilidade ao contágio de doenças nessa fase.

Nesse contexto, o presente estudo tem por objetivo verificar a responsabilidade estatal pela sua omissão diante das mazelas do sistema carcerário brasileiro, a partir do estudo de caso da situação da ala feminina do presídio Advogado Nilton Gonçalves, em Vitória da Conquista, observando as condições das presas que ali se encontram. Ademais, a pesquisa também se valerá da averiguação da responsabilidade do Estado perante a morte da detenta Dalva Santos da Silva, dentro do referido presídio, sem assistência médica, no ano de 2013.

Trata-se de pesquisa qualitativa em que a pesquisa bibliográfica é mesclada com entrevistas. Destarte, foram entrevistas estruturadas com detentas do presídio Advogado Nilton Gonçalves, em Vitória da Conquista, tendo por foco os efeitos da ausência da efetividade dos direitos funda- 
mentais da saúde e da dignidade humanas. Além disso, foram realizadas entrevistas com o diretor geral do presídio, Alessandro Oliveira, a fim de verificar as situações em que se encontra aquela unidade, destacando os paradigmas da realidade prisional para a concretude dos direitos do preso, garantidos pela ordem constitucional e pelos tratados internacionais dos quais o Brasil é signatário, como a Convenção Americana de Direitos Humanos de 1969.

As entrevistas servirão de base para analisar a responsabilidade do Estado por omissão da garantia dos direitos supracitados, à luz do estudo de caso da detenta, Dalva Santos da Silva, que morreu dentro da unidade prisional no ano de 2013 sem assistência médica. Somando-se a isso, será realizado um levantamento histórico-social da questão do sistema carcerário brasileiro e as mazelas do sistema penal.

Por fim cabe ressaltar que diante do objetivo de salvaguardar a ética da pesquisa e a intimidade dos entrevistados, os seus nomes permanecerão ocultos, sendo divulgado aqui apenas o conteúdo de suas entrevistas.

\section{AS CONDIÇÕES DO SISTEMA CARCERÁRIO BRASILEIRO E A (DES)CONSTRUÇÃO DO DIREITO PENAL}

O sistema carcerário brasileiro é traduzido como um verdadeiro caos em razão da superlotação e pela falta de condições físicas e psíquicas para a mínima existência humana. As condições das prisões do Brasil revelam espaços de disseminação de doenças e desumanidade com profundo desrespeito aos princípios constitucionais fundamentais à vida, à saúde e à dignidade humana, conforme preleciona Nucci (2010, p. 39-40).

Trata-se sem dúvida, de princípios regentes, cuja missão é a preservação do ser humano, desde o nascimento até a morte, conferindo-lhe autoestima e garantindo-lhe o mínimo existencial. 


\section{$[\ldots]$}

Para que o ser humano tenha sua dignidade preservada, torna-se essencial o fiel respeito aos direitos e garantias individuais. Por isso, esse princípio é a base e a meta do Estado Democrático de Direito, não podendo ser contrariado, nem alijado de qualquer cenário, em particular, do contexto penal e processual penal.

Diante disso, o Direito Penal deve estar interligado aos princípios que regem a Carta Magna para que não fira a dignidade humana nem desrespeitem os direitos humanos.

A partir dessa perspectiva, faz-se necessário compreender o campo de atuação dos direitos humanos e dos direitos fundamentais. Segundo as lições de Alexandre de Moraes (2015, p. 47), “os direitos humanos são universais, que conferem poder de existência digna, livre e igual de todos os seres humanos”. Os direitos fundamentais, por sua vez, são a positivação dos direitos humanos a partir do reconhecimento das legislações positivas - em especial pela Constituição da República Federativa de 1988 - que trazem a materialidade dos direitos humanos com as garantias individuais e coletivas.

Os direitos fundamentais formam, assim, um sistema principiológico que, na esfera penal, revelam-se como garantias a serem observadas pelo Estado quando for cominar e executar sanções penais. Desse modo, o Direito Penal brasileiro é fruto de uma construção legítima, abalizado pelos princípios que compõem o ordenamento jurídico, como afirma Luiz Antônio Rizzato Nunes $(2002,45)$ : “A dignidade é o primeiro fundamento de todo o sistema constitucional posto e o último arcabouço da guarida dos direitos individuais”. 
Diante disso, percebe-se que o princípio da dignidade da pessoa humana é o direito fundamental que deve ser observado e preservado em um Estado Democrático de Direito, uma vez que este princípio é uma qualidade integrante da condição humana, servindo de instrumento norteador para a elaboração e aplicação de regras.

Para limitar o exercício do ius puniendi do Estado, a Constituição de 1988 elencou garantias à integridade física e moral do preso, ao declarar,

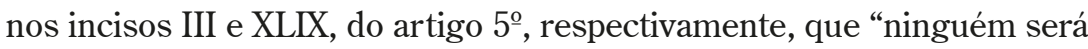
submetido à tortura ou a tratamento desumano ou degradante" e que "é assegurado ao preso a integridade física e moral”. Essas garantias reservam aos apenados a dignidade dentro do cárcere.

Apesar de ser considerado como base norteadora para a construção do Direito Penal, o princípio da dignidade da pessoa humana é constantemente violado nos sistemas prisionais brasileiros, que não garantem os direitos do preso e corrompem a real função da pena. $\mathrm{O}$ sistema jurídico-penal não permite que a pena seja um meio de prevenção contra o crime e um ambiente saudável para a preservação da vida humana, mas tem se tornado, como afirma Assis (2010, p. 1), “a verdadeira institucionalização da violência e disseminação de doenças, mapeado por um discurso de defesa social divulgado pelos meios midiáticos”.

Trata-se, portanto, de verdadeira crise do sistema penal, que passou a ser desconstruído em suas instituições ideológicas e concretas, como observa Leonardo Sica (2002, p. 22), que “o sistema penal, atrelado aos gastos dos governantes para a manutenção dos estabelecimentos penais, as condições desumanas dentro dos presídios, a superlotação e a corrupção interna, denotam um sistema fadado à falência”.

Nunes Júnior (2004, p. 78) afirma que o "direito à saúde é pressuposto básico para que haja dignidade humana" e acrescenta:

O princípio da universalidade aponta que todo ser humano, só por sê-lo, tem direito de acesso ao sistema público de saúde. Tal acesso, contudo, há de se dar em compasso com o princípio republicano, que proíbe 
tratamento diferenciado aos cidadãos. Só o acesso igualitário assegura a correta distribuição dos recursos públicos na área da saúde, promovendo, portanto, a equidade no sistema (2004, p. 79).

Para além da condição de direito fundamental, todavia, não se pode deixar de mencionar que a saúde é também dever do Estado. Essas questões aparecem explícitas no artigo 196 da Constituição Federal de 1988, na seção II, que trata da saúde, "A saúde é direito de todos e dever do Estado, garantido mediante políticas sociais e econômicas que visem à redução do risco de doença e de outros agravos e ao acesso universal e igualitário às ações e serviços para sua promoção, proteção e recuperação” e nas lições de Sarlet (2001, p. 92):

[...] impondo ao Estado a realização de políticas públicas que busquem a efetivação deste direito para a população, tomando-se, para, além disso, o particular credor de prestações materiais que dizem com a saúde, tais como atendimento médico e hospitalar, fornecimento de medicamentos, realização de exames, enfim, toda e qualquer prestação indispensável para a realização concreta deste direito à saúde.

Diante disso, percebe-se que é dever do Estado preservar a saúde dos presos, garantindo-lhes condições de vida saudável e assistência médica adequada. Essa premissa é fundamentada tanto na legislação internacional quanto na brasileira, conforme é estabelecido pela Lei de Execução Penal, em seu artigo 41, que assegura direitos e garantias ao preso:

Art. 37. Constituem direitos básicos e comuns dos presos condenados ou provisórios:

I - alimentação suficiente e vestuário;

II - atribuição de trabalho e sua remuneração;

III - Previdência Social;

IV - constituição de pecúlio;

$\mathrm{V}$ - proporcionalidade na distribuição do tempo para o trabalho, o descanso e a recreação; 
VI - exercício das atividades profissionais, intelectuais, artísticas e desportivas anteriores, desde que compatíveis com a execução da pena; VII - assistências materiais, à saúde, jurídica, educacional, social, psicológica e religiosa;

Essa perspectiva de proteção do preso encontra fundamento na ordem internacional em “As Regras Mínimas da ONU para o Tratamento de Prisioneiros”, que assegura, entre outras garantias, o direito a instalações limpas, adequadas, higiênicas, arejadas, salubres, a uma boa alimentação e à manutenção da higiene pessoal do preso. Essas Regras foram internalizadas no país pela Resolução n⿳ำ 14 , do Conselho Nacional de Política Criminal e Penitenciária, que criou as Regras Mínimas do Preso no Brasil e que determina assistência médica, farmacêutica, odontológica e psicológica aos detidos.

No âmbito nacional, além da Constituição Federal de 1988 e da Lei de Execução Penal, em 2002, mediante a Portaria no 628 (BRASIL, 2002), os ministérios de Estado da Saúde e da Justiça estabeleceram um Plano Nacional de Saúde no Sistema Penitenciário (PNSSP), visando a melhorias nas condições de saúde da população carcerária feminina e masculina do Brasil. Esse Plano foi alterado por meio da Portaria 1.777, de 2003, que prevê a inclusão da população carcerária no atendimento oferecido pelo Sistema Único de Saúde.

Outras duas resoluções do Conselho Nacional de Política Criminal e Penitenciária têm foco na preservação da saúde dos internos em estabelecimentos prisionais. A primeira é a $\mathrm{n}^{0} 7$, de 2003, alterada pela Resolução nº 6, de 2006, que estabelece Diretrizes Básicas Para as Ações de Saúde nos Sistemas Penitenciários, propondo adoção de medidas para prevenção e controle de doenças (tuberculose, DSTS-AIDS, hanseníase, hipertensão arterial e diabetes, saúde mental e bucal). A segunda, de $n^{\circ}$ 2, de 2008, propõe diretrizes básicas para a condução de presos durante o atendimento à saúde e condições mínimas de segurança para sua realização. 
Em se tratando da saúde feminina é importante ressaltar as necessidades físicas especiais que a ala feminina deve apresentar para garantir a saúde à mulher. A Carta Magna determina tratamento especial às mulheres detentas, com: a) estabelecimento próprio, adequado à sua condição, ou seja, as mulheres não podem cumprir pena junto com os presos do sexo masculino; b) respeito à sua condição pessoal, devendo ser respeitados os direitos e deveres inerentes à condição de mulher, assegurando às presas o direito de permanecerem com seus filhos durante o período da

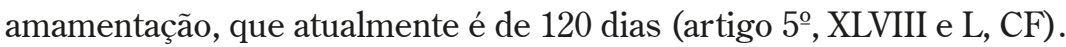

O que se percebe na realidade, entretanto, é o descaso à saúde da mulher de forma específica com relação aos cuidados de higiene, acometimento de doenças, respeito aos ciclos menstruais, que incorrem na sua fragilidade humana, que é duplamente penalizada com a sua pena propriamente dita e a situação concreta do sistema carcerário que não lhe garante condições dignas de saúde e assistência médica.

\section{A INAPLICABILIDADE DO PRINCÍPIO DA EFICIÊNCIA DA ADMINISTRAÇÃO PÚBLICA}

A Constituição Federal de 1998 informa em seu artigo 37 que a administração pública, tanto direta como indireta, de qualquer dos poderes da União, dos Estados, do Distrito Federal e dos municípios, deverá obedecer aos princípios de legalidade, impessoalidade, moralidade, publicidade e eficiência. Ademais, doutrinadores ressaltam a importância de tais princípios no norteamento das atividades administrativas, e alguns, como Meirelles (2011), acrescentam a estes mais alguns, decorrentes do sistema jurídico brasileiro, como os princípios da razoabilidade, proporcionalidade, ampla defesa, contraditório, segurança jurídica, motivação e supremacia do interesse público. 
O citado autor salienta que é por estes princípios que deverão se pautar todos os atos e atividades administrativas de todo aquele que exerce o poder público, funcionando como verdadeiros fundamentos para a ação administrativa. Acerca do princípio da eficiência, este foi acrescentado ao rol apresentado pelo artigo 37 mediante a Emenda Constitucional nำ 19 , e ganha seu destaque na medida em que exige que a atividade administrativa seja exercida com presteza, perfeição e rendimento funcional. Por ser fruto de uma inserção posterior, o princípio da eficiência é o mais moderno da função administrativa, e exige mais do que a mera legalidade, buscando também resultados positivos para o serviço público e um satisfatório atendimento das necessidades da comunidade e de seus membros.

Em acordo com a ponderação de Di Pietro (2016), o princípio da eficiência deve ser observado tanto no modo de atuação do agente público - do qual se espera o mais satisfatório desempenho e a busca pelos melhores resultados no exercício de suas atribuições - quanto em relação ao próprio modo de se organizar, estruturar e disciplinar a administração pública, também visando a melhores resultados na prestação do serviço público. Cumpre lembrar que a eficiência que rege a atuação pública difere daquela presente no setor privado. Isto porque o Estado não tem como objetivo central a obtenção de ganhos de caráter financeiro, mas sim uma gestão pautada em benefícios sociais e cumprimento das garantias do Estado Democrático de Direito.

Para aplicar o princípio da eficiência ao sistema carcerário brasileiro faz-se necessário delinear seus objetivos e pressupostos, para que possa compreender em que medida ele pode ser considerado eficiente. Tomando por base a questão da função da pena, o artigo 59 do Código Penal apresenta a seguinte redação: 
O juiz, atendendo à culpabilidade, aos antecedentes, à conduta social, à personalidade do agente, aos motivos, às circunstâncias e consequências do crime, bem como ao comportamento da vítima, estabelecerá, conforme seja necessário e suficiente para reprovação e prevenção do crime:

I - as penas aplicáveis dentre as cominadas;

II - a quantidade de pena aplicável, dentro dos limites previstos;

III - o regime inicial de cumprimento da pena privativa de liberdade;

IV - a substituição da pena privativa da liberdade aplicada, por outra espécie de pena, se cabível (BRASIL, 1940).

Da leitura deste artigo é possível concluir que o Código Penal brasileiro conjuga, na finalidade da pena, a necessidade de reprovação com a prevenção do delito. Em outras palavras, Greco (2014) esclarece que a legislação penal brasileira parte do pressuposto de que a pena deve reprovar o mal produzido pela conduta praticada pelo agente, bem como prevenir futuras infrações penais. Somado a isso, o artigo 38 do Código Penal decreta que "o preso conserva todos os direitos não atingidos pela perda da liberdade, impondo-se a todas as autoridades o respeito à sua integridade física e moral”. Conforme já citado, a Lei de Execução Penal (lei 7.210/84) também aborda a temática dos direitos do preso em seu artigo 41, garantindo, entre outros fatores, assistência material, à saúde, jurídica, educacional, social e religiosa.

Nesta linha de intelecção, um sistema prisional eficiente seria aquele que atendesse aos desígnios para o qual fora criado, devendo garantir minimamente os pressupostos da prevenção e repreensão à prática delitiva; assim como aquele que respeitasse as bases norteadoras de sua ação - como as garantias asseguradas aos presos. Ocorre, porém, que o dever-ser da administração pública em muito se afasta da realidade concreta, e o sistema prisional brasileiro não se distancia dessa realidade. Greco (2014) ratifica tal afirmativa ao apontar que os direitos garantidos ao preso talvez seja um dos artigos mais desrespeitados de nossa legislação penal, visto que a toda hora é testemunhada a humilhação e sofrimento 
daqueles que por algum motivo encontram-se no sistema carcerário. Segundo ele, isto ocorre não somente entre os presos provisórios, mas também entre aqueles que já foram condenados e cumprem sua pena nas penitenciárias estatais.

Ainda segundo o autor, embora a pena seja um mal necessário, o Estado quando faz valer o seu ius puniendi deve lembrar-se que o erro cometido pelo cidadão ao praticar o delito não permite que o Estado cometa outro, muito mais grave, ao tratá-lo como animal. Até porque, se uma das funções atribuídas à pena é a ressocialização do condenado, certamente num regime cruel e desumano isso não acontecerá.

Nucci (2014) também denuncia esta realidade, e afirma ser de conhecimento público e notório que vários presídios apresentam celas imundas e superlotadas, sem qualquer salubridade. Ressalta ainda que nestes locais, em completo desacordo ao estipulado em lei, inúmeros sentenciados contraem enfermidades graves, além de sofrerem violências de toda ordem.

Diante do exposto até aqui, constata-se que a administração pública tem falhado em pelo menos dois aspectos fundamentais da eficiência do sistema prisional: 1) em relação ao alcance da finalidade da pena, tendo em vista que um ambiente inóspito e desumano, sem as devidas assistências, não é capaz de ressocializar ninguém; 2) em relação à inaplicabilidade das garantias de condições dignas para os detentos, que embora presos, não perdem por isso sua condição humana.

\section{RESPONSABILIDADE EXTRACONTRATUAL POR OMISSÃO DO ESTADO}

Bandeira de Mello (2009) faz importante contribuição do tema ao esclarecer que a responsabilidade do Estado é uma lógica e inevitável consequência da noção de Estado de Direito, uma vez que se firma como corolário da submissão do poder público ao Direito. 
Em relação à responsabilidade conferida ao Estado, deve-se destacar introdutoriamente que esta abrange as três modalidades por meio das quais o poder estatal é repartido, ou seja, a responsabilidade administrativa, a jurisdicional e a legislativa, no entanto a responsabilidade decorrente do comportamento dos poderes Legislativo e Judiciário acaba incidindo apenas de forma excepcional, de modo que a responsabilidade do Estado por seus atos na administração acaba recebendo uma maior ênfase.

Importante ressalva faz Di Pietro (2016) a respeito da necessidade de se falar sempre em responsabilidade do Estado, pessoa jurídica, e não responsabilidade da administração pública. É relevante esta distinção, uma vez que a administração pública não possui personalidade jurídica e, assim sendo, não é titular de obrigações e direitos na ordem civil, diferentemente do Estado, pessoa jurídica. Outro destaque importante é que a responsabilidade estatal será sempre de ordem civil, podendo ocorrer tanto por ação quanto por omissão do poder público, desde que gerem algum dano à terceiro. De igual forma, a responsabilização poderá ocorrer tanto por atos ilícitos quanto por aqueles que, embora lícitos, acarretem a algumas pessoas ônus maior do que o imposto a toda a coletividade, ou ofereçam a pessoas determinadas um dano anormal e específico.

Com base nestes pressupostos, a referida autora desenvolve o conceito de responsabilidade como "a obrigação de reparar danos causados a terceiros em decorrência de comportamentos comissivos ou omissivos, materiais ou jurídicos, lícitos ou ilícitos, imputáveis aos agentes públicos” (DI PIETRO, 2016, p. 716).

Sendo o Direito um ramo de conhecimento que se modifica no tempo e no espaço, a questão da responsabilidade estatal recebe tratamentos diversos entre os sistemas e as várias teorias desenvolvidas sobre o tema durante a construção do estudo jurídico-administrativo. Constituindo o estudo em questão, todavia, voltado à realidade local, haverá realce no tratamento da doutrina e da jurisprudência brasileiras acerca do tema. 
A legislação pátria trata o tema tanto no âmbito civil quanto no constitucional. O artigo 37, $\S 6^{\circ}$, da Constituição Brasileira de 1988 tem a seguinte disposição:

As pessoas jurídicas de direito público e as de direito privado prestadoras de serviços públicos responderão pelos danos que seus agentes, nessa qualidade, causarem a terceiros, assegurado o direito de regresso contra o responsável nos casos de dolo ou culpa.

O Código Civil também abrange o tema, embora sem fazer referência às pessoas jurídicas de Direito privado que prestam serviço público. Preleciona em seu artigo 43 que: "pessoas jurídicas de direito público interno são civilmente responsáveis por atos dos seus agentes que nessa qualidade causem danos a terceiros, ressalvado direito regressivo contra os causadores do dano, se houver, por parte destes, culpa ou dolo".

Nesta linha de intelecção, Di Pietro (2016) depreende da citada norma constitucional duas regras acerca da responsabilidade: 1) a responsabilidade objetiva do Estado, 2) a responsabilidade subjetiva do agente público. Destrinchando tais conceitos de responsabilidade recorrendo a Bandeira de Mello (2009), o autor define a responsabilidade objetiva como a obrigação de indenizar que se incumbe a alguém em razão de procedimento lícito ou ilícito que produziu alguma lesão na esfera juridicamente protegida de outrem, bastando, para configurá-la, a mera relação causal entre o comportamento e o dano. Acerca da responsabilidade subjetiva, o autor informa que seu elemento tipificador está na existência da culpa civil, não bastando uma mera objetividade de um dano, faz-se necessário o nexo de causalidade entre o fato e a ação do autor, relacionado com a quantidade de culpabilidade no ato.

Em relação à regra de responsabilidade objetiva trazida pela Constituição, Di Pietro (2016) informa que esta exige a existência de cinco requisitos para sua configuração. $O$ primeiro deles é que o ato lesivo deve ser praticado por agente de pessoa jurídica de Direito público ou pessoa 
jurídica de Direito privado prestadora de serviço público. Já o segundo critério consubstancia-se na necessidade de que as entidades de Direito privado prestem um serviço público, o que exclui, por exemplo, as entidades da administração indireta que executem atividade econômica de natureza privada, somente respondendo objetivamente aquelas que, de fato, prestem serviço público. O terceiro critério é que seja causado dano a terceiro (independentemente da qualidade de usuário de serviço público) em decorrência da prestação, revelando-se, portanto, a necessidade de nexo entre causa e efeito. $\mathrm{O}$ quarto critério é que o dano seja causado por agente das citadas pessoas jurídicas, sem importar o título sob o qual prestam o serviço. Por fim, o quinto e último critério é a necessidade de que o agente aja, efetivamente, no exercício de suas funções.

Ainda seguindo os apontamentos da citada autora, existem situações que podem atenuar ou mesmo afastar a responsabilidade civil do Estado. Em relação às causas excludentes, são elas a força maior, a culpa da vítima e a culpa de terceiros. Em relação à força maior e à culpa de terceiros, cabe a ressalva de que a responsabilidade do Estado poderá continuar a incidir se, aliada a tais excludentes, ocorrer omissão do poder público na realização de um serviço, possibilidade na qual a responsabilidade será subjetiva, e não objetiva. Em relação à atenuação da responsabilidade estatal, esta se dará em caso de culpa concorrente da vítima.

Quanto à reparação do dano causado a terceiros, esta poderá ocorrer na própria esfera administrativa quando a administração pública assumir desde logo sua responsabilidade e não houver divergências acerca do valor da indenização. Caso contrário, o terceiro vitimado deverá promover ação de indenização contra a pessoa jurídica que lhe causou o dano. O réu, por sua vez, poderá mover ação regressiva contra o seu agente, desde que este tenha agido com dolo ou culpa, em razão de sua responsabilidade subjetiva. 
Conforme já abordado, a responsabilidade estatal pode incidir tanto em razão de atos comissivos quanto de atos omissivos. No tocante aos atos omissivos, Di Pietro (2016) ressalta que os danos, em regra, não são causados diretamente pelos agentes públicos, são ocasionados por fatos da natureza ou de terceiros, mas que poderiam ter sido minorados ou evitados se houve omissão do Estado quando este tinha o dever de agir.

Com base nisso, para uma possível responsabilização estatal por via omissiva, é importante respeitar os princípios da reserva do possível e da razoabilidade. Em outras palavras, deve-se levar em conta o que seria razoável se exigir do Estado para impedir o dano, não havendo que se falar em sua responsabilização quando, embora houvesse o dever de agir, faltasse a sua possibilidade.

Ainda acerca da responsabilidade por omissão, existe controvérsia acerca da sua possibilidade, assim como acerca da espécie de responsabilidade que deve incidir nesses casos. Parte da doutrina entende que o artigo 37, $\S 6^{\circ}$, da Constituição abarca os atos comissivos e omissivos do agente público, de modo que, para a sua aplicação, basta comprovar a existência do nexo de causalidade entre o ato comissivo/omissivo e o dano causado a terceiros, não havendo que se discutir acerca do dolo ou culpa. Para esta corrente a responsabilidade é, portanto, objetiva.

Para outra parte da doutrina, no entanto, a responsabilidade em casos de omissão é subjetiva, devendo-se aplicar, nesses casos, a teoria da culpa anônima do serviço público ou da culpa do serviço público, posto que seria indiferente saber a identidade do agente público responsável. Para esta segunda corrente, o Estado deve responder quando o serviço público não funciona embora devesse funcionar, ou quando funciona de forma ineficiente, hipóteses em que restará configurada a omissão danosa. Neste estudo, dada a controvérsia sobre o tema também na jurisprudência 
brasileira, será adotada a responsabilidade subjetiva do Estado em casos de omissão, posicionamento consonante com Bandeira de Mello (2009) e Di Pietro (2016), embora componentes da corrente minoritária.

De tal modo, Bandeira de Mello defende seu posicionamento acerca da responsabilidade subjetiva, utilizando-se do seguinte argumento:

Com efeito, se o Estado não agiu, não pode, logicamente, ser ele o autor do dano. E, se não foi o autor, só cabe responsabilizá-lo caso esteja obrigado a impedir o dano. (...) Deveras, caso o poder público não estivesse obrigado a impedir o acontecimento danoso, faltaria razão para impor-lhe o encargo de suportar patrimonialmente as consequências da lesão. Logo, a responsabilidade estatal por ato omissivo é sempre responsabilidade por comportamento ilícito. E, sendo responsabilidade por ato ilícito, é necessariamente responsabilidade subjetiva, pois não há conduta ilícita do Estado (embora do particular possa haver) que não seja proveniente de negligência, imprudência ou imperícia (culpa) ou, então, deliberado propósito de violar a norma que constituía em dada obrigação (dolo). Culpa e dolo são justamente as modalidades de responsabilidade subjetiva. (2009, p. 1.012-1.013)

Outra questão acerca do tema diz respeito à exigibilidade ou não de dano imediato e direto para a incidência da responsabilidade por omissão do Estado. Isto é, há necessidade de que o efeito esteja contemporaneamente ligado à causa, ou os danos remotos também podem ser admitidos? Segundo Di Pietro (2016), o Supremo Tribunal Federal vinha adotando, para a configuração do nexo de causalidade, a teoria do dano direto e imediato, ou seja, a necessidade de uma proximidade temporal entre a causa e o dano, devendo haver ligação direta entre eles. Ocorre, porém, que tal entendimento parece estar se alterando, já sendo possível encontrar julgados do Supremo Tribunal Federal em que foram admitidas cadeias temporais mais amplas entre a causa e o dano. 


\section{PRESÍDIO REGIONAL ADVOGADO NILTON GONÇALVES, VITÓRIA DA CONQUISTA - BA}

O presídio Nilton Gonçalves é uma unidade prisional em funcionamento em Vitória da Conquista, situado no bairro Conveima. Foi inaugurado no ano de 1993, e ao longo do tempo recebeu reformas para adequar as condições de instalação devido às lotações do local.

Segundo o diretor geral do presídio, Alexsandro Oliveira, a unidade possui capacidade para abrigar 187 presos, porém, atualmente, comporta 390, entre os quais 25 são mulheres. Além do problema evidente de superlotação, o presídio enfrenta problemas de estrutura antiga e, hoje, com o desenvolvimento da cidade, acaba se situando dentro de um bairro residencial, fazendo fronteira direta com as ruas da localidade do bairro Conveima I.

Essa realidade acaba trazendo o medo e a insegurança para os moradores da região, que acabam presenciando fugas e rebeliões no presídio. Ademais, a segurança interna também se torna prejudicada com o acesso fácil de objetos jogados por cima dos muros da unidade.

Outro problema enfrentado é a sobrecarga dos agentes penitenciários em decorrência da superlotação em espaços insalubres, o que acaba resultando em rebeliões, a exemplo da ocorrida em março de 2016, em decorrência da falta de água dentro da unidade prisional.

Diante dessa realidade, constatou-se que a insalubridade e a falta de serviços básicos para a sobrevivência humana são fatores que contribuem para a não efetividade da ressocialização do preso. Notou-se que não há espaços para atividades de lazer e educativas, o que acaba aumentando o estresse daqueles que se encontram aprisionados em tais condições. 
Em se tratando das questões de saúde, o presídio não possui o mínimo suporte para o atendimento básico de saúde. Não há posto médico no local, então, os presos que necessitam de atendimento médico-hospitalar são encaminhados para o posto de saúde do bairro, acarretando na possibilidade de fuga do preso e na insegurança da população da região.

Segundo o diretor da unidade, as condições do presídio revelam a precariedade do sistema carcerário e o completo descaso com a integridade física dos presos, verificando-se a omissão do Estado de garantir os direitos fundamentais e mínimos para a existência humana. Vejamos:

Diretor do Presídio Nilton Gonçalves: Esse presídio representa o verdadeiro descaso do Estado com o sistema carcerário. Não há de se falar em saúde humana, se nem como humanos são tratados os presos. Colocar uma pessoa atrás dessas grades não me faz sentir cumprindo a justiça. Isso representa muito mais uma aflição e tortura para o ser humano.

Para Alexsandro Oliveira, o presídio só está funcionando nas reais condições por esforço dos agentes penitenciários que se comprometem, muitas vezes, em ceder mantimentos e água para os detentos. Vejamos:

Diretor do Presídio Nilton Gonçalves: Em tempos de crise hídrica, esse presídio vira de ponta à cabeça sem água. Não tem como sobreviver fora da prisão sem água, imagine em condições de superlotação. É preciso, muitas vezes, o esforço dos agentes para comprar um caminhão pipa para encher as caixas de água e garantir, pelo menos, o banho.

Tratando da realidade da ala feminina e as condições de saúde da unidade, o diretor afirmou que é um local improvisado pelo Estado para a alocação das detentas que aguardam sentenças ou sentenciadas que estão à espera vagas nas penitenciárias de Salvador e Jequié. Diante disso, percebemos que não há qualquer assistência dentro das celas, que são abarrotadas e insalubres, conforme exposto a seguir: 
CONDIÇ̃̃ES PRECÁRIAS DE SAÚdE NA ALA FEMININA DO PRESÍdIO NILTON GONÇALVES:

Uma História de Abandono e Sofrimento

Diretor do Presídio Nilton Gonçalves: A situação da ala feminina é a completa omissão do Estado. Não há qualquer respeito ao direito de tratamento especial para as mulheres, como utensílios de higiene, local para as crianças, idas ao médico. Tudo isso se torna mais penoso para a mulher, que possui ciclos menstruais e não tem nem como pensar como ficam as celas nesses períodos.

Segundo a maioria das entrevistadas, as situações das celas são de superlotação, falta de higiene e sem condições de garantir os direitos fundamentais do cidadão. Vejamos:

M. C. R: Isso aqui é desumano. Somos muitas em uma única cela. A gente sabe que não é culpa dos agentes daqui. Eles nos ajudam no que podem. O problema vem de longe. Vem do governo que não está nem aí para o que passamos aqui. Para eles, não fazemos parte da sociedade. Não é vantajoso para eles garantir condições de vida dentro das cadeias.

N. X. D: Não tem qualquer tipo de higiene. Não temos médicos sempre disponíveis. Temos que ir no posto do bairro. $\mathrm{O}$ que há é um crescente número de doenças entre nós.

A fim de verificar a responsabilidade do Estado pela situação do presídio, foi feito o questionamento sobre as garantias de assistência médica e o cuidado especial que deve ser dado à ala feminina por suas condições físicas e ciclos biológicos inerentes ao próprio corpo humano. Constatamos que, pelo exposto pelas entrevistadas, as condições da unidade são precárias:

T. F. S: Não recebemos visitas de médicos. Não há ala médica aqui dentro. Vamos ao posto de saúde do bairro, quando a situação fica muito difícil.

C. R. S: No ciclo menstrual, isso aqui fica um horror. As celas são imundas. É um profundo desrespeito com a dignidade da mulher, acima de tudo. 
Com relação à ala feminina no presídio Nilton Gonçalves, esta foi uma adaptação diante da necessidade concreta, uma vez que a unidade mais próxima seria na cidade de Jequié/BA, o que provocaria um desgaste muito maior para as presas provisórias e para a família e filhos das detentas, que aguardam julgamento na cidade de Vitória da Conquista/BA.

Importante salientar que no presídio encontram-se detidas as presas acauteladas e sentenciadas que aguardam transferência para as unidades prisionais de Salvador/BA e Jequié/BA.

A ala feminina conta com um pátio e 5 celas, com capacidade para 4 detentas em cada, somando um total de 20 vagas femininas. Duas celas, contudo, encontram-se interditadas por motivos estruturais, o que leva, consequentemente, ao alojamento das 25 presas em apenas uma única cela, uma vez que as outras foram cedidas para a ala masculina.

Toda essa situação demonstra o descaso do poder público com a dignidade humana dos presos, que vivem empilhados em poucas celas, sem qualquer preservação das condições mínimas de sobrevivência do ser humano. Percebe-se a completa omissão do Estado com a vida humana ali inserida. O Direito Penal, sob essas instalações, acaba sendo mais cruel e desumano, revelando-se mais aflitivo e punitivo do que a própria pena a ser imposta pelo crime cometido pelo apenado.

No dia 24 de junho de 2013, as detentas encontraram a colega, Dalva Santos da Silva, de 47 anos, morta dentro da cela. Durante a chamada das detentas, Dalva Santos não respondeu, foi então que as carcereiras entraram na cela e acionaram o Serviço de Atendimento Móvel de Urgência (Samu).

O médico do Serviço constatou a morte. A suspeita é que ela tenha sofrido um enfarte. Segundo o diretor do presídio, constatou-se que a mulher sofreu um enfarte de 2 horas da madrugada, que se agravou com a cela úmida e insalubre em que se encontrava. Conforme depoimento de 
companheiras de cela, Dalva havia se consultado com o médico do posto de saúde do bairro Conveima, alegando mal-estar uma semana antes. Eis os relatos:

J. T. S: Dalva já estava morta quando a encontramos pela manhã. Durante a noite, ela se queixou de frio. Lembro que uma semana antes, ela havia se queixado de dores e foi ao posto de saúde do bairro, mas voltou sem receita médica. Eu acho que o frio e as condições da cela podem ter influenciado na morte prematura dela, porque a pessoa que passa mal e fica exposta a essas condições, não tem outra saída senão a morte mesmo.

D. F. S: Fizemos protesto por ela. É horrível pensar que uma pessoa morreu sem assistência médica. Ela não teve nem o direito de ser socorrida a um hospital. Já estava morta pela manhã. Ela mesma disse que tinha problemas de saúde de coração e não sabia como viveria nas condições das celas.

Diante disso, a omissão do Estado fica evidente no relato das detentas, uma vez que, se houvesse assistência médica no presídio a morte da mulher poderia ter sido evitada.

\section{CONSIDERAÇÕES FINAIS}

Em suma, percebemos com as entrevistas coletadas de forma qualitativa, que de maneira semelhante ao que ocorre em outras regiões do país, a regência do presídio Nilton Gonçalves desconhece qualquer eficiência em relação às funções ressocializadoras da pena, funcionando apenas como uma punição degradante, que em nada contribui para a evolução espiritual, social e educacional do preso.

As condições de insalubridade em que vivem as detentas desta instituição prisional revelam a ineficiência também em relação às garantias legislativas acerca dos direitos dos presos. Esta realidade denuncia o dis- 
tanciamento da administração em relação ao seu dever de eficiência, uma vez que esta ignora o dever-ser das condições de cumprimento de pena, tornando a letra da lei algo muito distante da realidade material.

Em relação ao óbito da detenta, é inegável que esta situação enseja a responsabilidade extracontratual do Estado, em sua modalidade omissiva. Em acordo com as características desta modalidade de responsabilização, abordadas no presente estudo, a condição de cardíaca da detenta, embora preexistente, foi agravada por conta do funcionamento ineficiente de um serviço que o Estado estava obrigado a prestar dentro dos moldes legais. Resta configurada, portanto, uma omissão danosa do Estado.

Neste diapasão, o presente artigo concluiu que a situação do presídio Nilton Gonçalves revela a completa omissão do Estado para as presas, que se encontram confinadas em celas insalubres e superlotadas. Diante do contexto ora delineado fica evidente que a responsabilidade estatal também deve ser adotada para a situação atual e contínua de vida das detentas, revelando-se possível a indenização por danos morais sofridos todos os dias pela lesão ao direito à saúde e a vida digna.

\section{REFERÊNCIAS}

ASSEMBLEIA LEGISLATIVA. Comissão de Cidadania e Direitos Humanos. Relatório azul 2009: garantias e violações dos direitos humanos. Porto Alegre: Corag, 2009. Disponível em: <http://www.al.rs.gov.br/Download/CCDH/ RelAzul/relatorio_azul\%202009. pdf//>. Acesso em: 23 ago. 2016.

. Comissão de Cidadania e Direitos Humanos. Relatório Azul 2006: garantias e violações dos direitos humanos. Porto Alegre: Corag, 2006.

ASSIS, Rafael Damaceno de. A realidade atual do sistema penitenciário brasileiro. Disponível em: <http://br.monografias.com/trabalhos908/a-realidade-atual/a-realidade-atual.shtml//>. Acesso em: 26 jul.2010. 
BANDEIRA DE MELLO, Celso Antônio. Curso de Direito Administrativo. 26. ed. São Paulo: Malheiros Editores, 2009.

BRASIL. Código Penal de 1940. Disponível em: <http://www.planalto.gov.br/ ccivil_03/Decreto-Lei/Del2848.htm//>. Acesso em: 20 ago. 2016.

. Constituição (1988). Constituição da República Federativa do Brasil. Brasília, DF: Senado, 2013.

. Ministérios de Estado da Saúde e da Justiça. Portaria interministerial no 628/2002. Salvador: MPBA, 2002. Disponível em: <http://www.mp.ba.gov. $\mathrm{br} /$ atuacao/cidadania/gesau/legislacao/temas/penitenciario/portaria_interministerial_628_02.pdf//>.Acesso em: 21 ago. 2016.

DI PIETRO, Maria Sylvia Zanella. Direito Administrativo. 29. ed. Rio de Janeiro: Editora Forense, 2016.

GRECO, Rogério. Curso de Direito Penal - Parte Geral. 16. ed. Rio de Janeiro: Editora Impetus, 2014. V. 1.

LEI 7.210/1984. Dispões sobre a Lei de Execução Penal. Disponível em: <// http://www.planalto.gov.br/ccivil_03/leis/L7210.htm//>. Acesso em: 20 ago. 2016.

MEIRELLES, Hely Lopes. Direito administrativo brasileiro. 35. ed. Atualização Eurico de Andrade Azevedo, Délcio Balestero Aleixo e José Emmanuel Burle Filho. São Paulo: Malheiros Editores, 2011.

. Ministério da Saúde. Secretaria de Atenção à Saúde. Departamento de Ações Programáticas Estratégicas. Plano nacional de saúde no sistema penitenciário. Brasília: Ministério da Saúde, 2004.

Ministério Público Federal. CPI do sistema carcerário: relatório final.

Brasília: MPF, 2008. Disponível em: <http://pfdc.pgr.mpf.gov.br/atuacao-e-conteudos-de-apoio/publicacoes/sistema-prisional/relatorio-final-cpi-sistema-carcerario-2008>. Acesso em: 19 ago. 2016.

MORAES, Alexandre. Constituição do Brasil interpretada e legislação constitucional. 5. ed. São Paulo: Atlas, 2015. 
NOGUEIRA, Péricles Alves; ABRAHÃO, Regina Maura Cabral de Melo. A infecção tuberculosa e o tempo de prisão da população carcerária dos Distritos Policiais da zona oeste da cidade de São Paulo. Revista Brasileira de Epidemiologia, São Paulo, v. 12, n. 1, p. 30-38, mar. 2009.

NUCCI, Guilherme de Souza. Manual de Direito Penal. 10. ed. Rio de Janeiro: Editora Forense, 2014.

. Manual de Processo Penal e Execução Penal. 10. ed. São Paulo: Editora Revista dos Tribunais, 2010.

NUNES JÚNIOR, Vidal Serrano. O direito à saúde e a efetividade dos direitos sociais. Revista do Instituto de Pesquisas e Estudo de Bauru/SP, São Paulo, n. 41, p. 77-79, set./dez. 2004.

NUNES, Luiz Antônio Rizzato. O princípio constitucional da dignidade da pessoa humana. São Paulo: Saraiva, 2002.

ORGANIZAÇÃO DAS NAÇÕES UNIDAS (ONU). Regras minimas para o tratamento dos prisioneiros. Genebra: ONU, [19-]. Comissão de Direitos Humanos da ONU no Brasil, Observação Geral no 20 (2015). Disponível em: http: <//www.onu.gov.br//>. Acesso em: 22 jul. 2015.

SARLET, Ingo Wolfgang. Dignidade da pessoa humana e direitos fundamentais. Porto Alegre: Livraria do Advogado, 2001.

SICA, Leonardo. Direito Penal de emergência e alternativas à prisão. São Paulo: Revista dos Tribunais, 2002.

ZAGO, L. H. O método dialético e a análise do real. Kriterion: Revista de Filosofia, Belo Horizonte, v. 54, n. 127, p. 109-124, jun. 2013. Disponível em: <//www. dx.doi.org/10. 1590/S0100-512X2013000100006/>. Acesso em: 10 ago. 2016. 